\title{
Positive selection of antibiotic-producing soil isolates
}

\author{
Teresa A. Huck, ${ }^{1} \uparrow$ Neil Porter $^{2}$ and Michael E. Bushell ${ }^{1 *}$ \\ ${ }^{1}$ Microbial Physiology Group, School of Biological Sciences, University of Surrey, Guildford GU2 5XH, UK \\ ${ }^{2}$ Xenova Ltd, 545 Ipswich Road, Slough SL1 4EQ, UK
}

(Received 18 April 1991; revised 3 July 1991; accepted 24 July 1991)

\begin{abstract}
Stepwise discriminant analysis was used to identify the most powerful selective substrates which could be used to formulate media capable of enriching for antibiotic-producing soil isolates. This was achieved by characterizing a collection of 74 soil bacteria, including eubacteria and actinomycetes, according to their ability to produce antibacterial antibiotics and their growth responses to 43 physiological and nutritional tests. The characters which were selective for actinomycetes relative to eubacteria included growth on proline $(1 \%, w / v)$ and humic acid $(0 \cdot 1 \%)$ as sole sources of both carbon and nitrogen, growth on nitrate as a nitrogen source, and growth at pH 7.78.0. Growth on proline (1\%) and humic acid (0.1\%) as sole carbon/nitrogen sources, growth on asparagine as a nitrogen source, and growth in the presence of vitamins were among the characteristics which allowed antibioticproducing actinomycetes to be differentiated from non-antibiotic-producing strains. Several simple isolation media which incorporated the selective substrates identified by discriminant analysis succeeded in increasing the proportion of actinomycetes isolated from soil samples. Furthermore, the percentage of isolates capable of antibiotic production was considerably increased.
\end{abstract}

\section{Introduction}

Actinomycetes are prolific producers of antibiotics and other bioactive compounds. They have provided over two-thirds of the naturally occurring antibiotics discovered and continue to be a major source of novel and useful compounds (Berdy, 1989). Reisolation of strains has, however, increased the difficulty of isolating cultures that produce novel and useful secondary metabolites (Bushell, 1982). This has necessitated the development of more directed and innovative selective isolation techniques in natural product screening programmes (Bushell, 1983).

In natural environments such as soil and water, the presence of large numbers of eubacteria may hinder the isolation of actinomycetes. Therefore, actinomycetes are frequently isolated by selecting against unwanted strains ('negative' selection), often with the use of inhibitors or physical pretreatments such as drying and heating, rather than by 'positive' selection through growth. Over the past 20 years, the inclusion of antibiotics in isolation

†Present address: Thermophile Research Unit, University of Waikato, Private Bag 3105, Hamilton, New Zealand.

Abbreviation: SDA, stepwise discriminant analysis. media has become a widespread method of engendering medium specificity (reviewed by Nolan \& Cross, 1988) and has led to the isolation of numerous hitherto unisolated strains. Okami \& Hotta (1988) described screens based on self-resistance of antibiotic producers, a technique with potential for detecting new examples of producers of existing groups of antibiotics.

Considerable information concerning antibiotic resistance and the nutritional requirements of actinomycete genera and species has been provided by numerical taxonomic studies. Such information may be used for selective medium design where desired groups of actinomycetes exhibit unique responses to physiological tests. Alternatively, in an innovative approach to medium design, Vickers et al. (1984) sought characters from the database of Williams et al. $(1983 a, b)$ that selected against the commonly isolated soil streptomycete Streptomyces albidoflavus. By selectively reducing numbers of this group on soil isolation plates, rarer species developed more readily as a consequence of reduced competition. Taxonomic databases represent a convenient source of information for medium design; however, since they are not constructed for this purpose there are several disadvantages in using them to isolate actinomycetes from natural environments. The most diagnostic tests for a particular group of organisms may 
not always be applicable to inclusion in isolation media. Furthermore, a data matrix used for the classification of actinomycetes does not take into account the reactions of other members of the natural population to the same tests. Eubacteria, for example, are frequently troublesome on soil dilution plates as they are often present in larger numbers and tend to grow faster than actinomycetes. Omission of data concerning a large proportion of the natural population will inevitably lead to an unreliable model for the design of isolation media. Additionally, the ability to produce antibiotics is strain specific and not species specific. Therefore, taxonomic information is not necessarily of value for the discovery of producers of new metabolites. There is thus a need for more appropriate databases to be constructed specifically for the design of isolation and culture media.

In previous studies, we have applied taxometric methods to eliminate recurring producers of known metabolites in antibiotic screens (Bushell \& Nisbet, 1981) and for the design of selective isolation conditions for Streptomyces mutants with improved antibiotic titre (Onadipe \& Bushell, 1987). In this work, an attempt was made to find substrates which would give soil actinomycetes a growth advantage over other common soil bacteria. A nutritional and physiological study measured the growth responses of a variety of soil micro-organisms (actinomycetes and eubacteria) to a number of different carbon and nitrogen sources in the presence of a variety of trace metals and vitamins. Resistance to antibiotics was not included in the study since our objective was to investigate the extent to which actinomycetes (and, in particular, antibiotic-producing strains) could be selected in the absence of inhibitors. Results from this study were used to form a database which was analysed using stepwise discriminant analysis (SDA). Selective isolation conditions were sought for actinomycetes compared to eubacteria and for antibiotic-producing actinomycetes compared to non-antibiotic-producing actinomycetes.

\section{Methods}

Strains. The micro-organisms used in this study were isolated from the A horizon of a sandy barley field soil (Puttenham, Surrey, England) by dilution plating the air-dried and homogenized soil samples on a range of isolation media. Isolation media were: soil extract agar (Gordon \& Mihm, 1962); yeast extract/malt extract (YEME) agar (Pridham et al., 1957) plus soil extract supplement $\left(250 \mathrm{ml} \mathrm{l}^{-1}\right)$ prepared by the method of Gordon \& Mihm (1962); nutrient agar (Oxoid); starch/casein/nitrate agar (Kuster \& Williams, 1964); and M3 medium (Rowbotham \& Cross, 1977). Cycloheximide $\left(50 \mu \mathrm{g} \mathrm{ml}^{-1}\right)$ and nystatin $\left(50 \mu \mathrm{g} \mathrm{ml}^{-1}\right)$ were added to media to inhibit fungi. The $\mathrm{pH}$ of each medium was adjusted to 7.2 to match that of the soil sample. After incubation for 4 weeks at $28^{\circ} \mathrm{C}$ a total of 280 actinomycete colonies and 75 eubacterial colonies were isolated. Actinomycetes were purified, stored and recovered on YEME agar, and eubacteria on nutrient agar.
The isolates were stored at $-20^{\circ} \mathrm{C}$ in glycerol/water $(15: 85, \mathrm{v} / \mathrm{v})$. Forty-nine actinomycetes were selected at random except that apparent duplicate isolates, according to the colour grouping method of Williams et al. (1969), were rejected so that the 49 actinomycete strains used were morphologically dissimilar. The cell walls of the actinomycete isolates were analysed by the method of Lechevalier \& Lechevalier (1970) to identify the diamino acid constituent of the peptidoglycan. Based on the results, 48 out of the 49 actinomycete isolates were identified as streptomycetes. Of the 75 non-actinomycete bacteria (eubacteria) isolated, 25 were selected for study on the basis of varied oxidase, catalase, $\mathrm{O} / \mathrm{F}$ and Gram reactions.

Measurement of antimicrobial activity. The ability of isolates to produce antibiotic substances was measured by an agar droplet overlay bioassay method. A peristaltic pump was used to dispense molten YEME agar in $1 \mathrm{ml}$ volumes which were dropped aseptically into square Petri dishes to produce button-shaped agar discs $15 \mathrm{~mm}$ in diameter. Each disc was inoculated with a test isolate and the Petri dishes were then incubated in a water-saturated atmosphere at $28^{\circ} \mathrm{C}$ for $5 \mathrm{~d}$. The ability of the test strains to produce antibiotic substances was measured by overlaying the droplets with nutrient agar seeded with one of three challenge organisms (Staphylococcus aureus Oxford $\mathbf{H}$ Strain VI, Escherichia coli $\mathrm{K} 12$, and an $E$. coli strain known to be supersensitive to $\beta$-lactam antibiotics). Tetrazolium salts $(2 \%, w / v$, triphenyltetrazolium chloride in DMSO) were added at a final concentration of $3 \%(\mathrm{v} / \mathrm{v})$ to the overlay so that clear zones of inhibition were easier to measure because of contrast to red areas where growth had occurred. After $18 \mathrm{~h}$ incubation at $37^{\circ} \mathrm{C}$ the dishes were examined for zones of inhibition. The test isolates were considered to be antibiotic producers if inhibitory activity was detected against any of the three challenge bacteria.

Utilization of carbon sources. Test carbon sources were added to ISP 9 carbon utilization agar (Shirling \& Gottleib, 1966). Glucose, maltose, starch, carboxymethylcellulose, methanol and glycerol were incorporated at concentrations to give carbon equivalence to $10 \mathrm{~g} \mathrm{l}^{-1}(1 \%, \mathrm{w} / \mathrm{v})$ glucose. The propionate concentration was equivalent to $0.1 \%(w / v)$ glucose.

Utilization of combined carbon and nitrogen sources. This test was carried out on a carbon utilization agar similar to the above but with the nitrogen source $\left[\left(\mathrm{NH}_{4}\right)_{2} \mathrm{SO}_{4}\right]$ omitted. Aspartate, threonine and proline were tested at a carbon level equivalent to $10 \mathrm{~g} \mathrm{I}^{-1}(1 \%, \mathrm{w} / \mathrm{v})$ glucose whilst humic acid (Aldrich) was tested at levels equivalent to both $1 \%$ and $0.1 \%(\mathrm{w} / \mathrm{v})$ glucose.

Utilization of nitrogen sources. The ability of strains to grow in the presence of a number of nitrogen sources was tested using a basal medium containing: $10 \mathrm{~g}$ glucose, $1.0 \mathrm{~g} \mathrm{~K}_{2} \mathrm{HPO}_{4}, 0.5 \mathrm{~g} \mathrm{MgSO}_{4}, 1.0 \mathrm{~g}$ $\mathrm{NaCl}$ and $15 \mathrm{~g}$ agar per litre. All nitrogen sources (asparagine, glutamic acid, arginine, alanine, $\mathrm{NaNO}_{3}, \mathrm{NaNO}_{2}$ and $\mathrm{NH}_{4} \mathrm{Cl}$ ) were tested at a

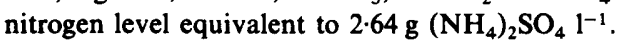

Growth tests. Growth was tested at various temperatures and $\mathrm{pH}$ values, in the presence of various chemical inhibitors and vitamins, and in the absence of various trace metals. The inorganic salts/glucose medium (ISG) used consisted of: $10 \mathrm{~g}$ glucose, $1.0 \mathrm{~g} \mathrm{~K}_{2} \mathrm{HPO}_{4}, 1.0 \mathrm{~g}$ $\mathrm{MgSO}_{4} .7 \mathrm{H}_{2} \mathrm{O}, 1.0 \mathrm{~g} \mathrm{NaCl}, 1.2 \mathrm{~g} \mathrm{NH}_{4} \mathrm{NO}_{3}, 2.0 \mathrm{~g} \mathrm{CaCO}_{3}$ and $15 \mathrm{~g}$ agar per litre. To investigate growth at different temperatures, unamended ISG medium was incubated at $28^{\circ} \mathrm{C}$ or $30^{\circ} \mathrm{C}$. The ability of the organisms to grow at different $\mathrm{pH}$ values was measured using ISG medium modified with either $\mathrm{NaOH}$ or $\mathrm{HCl}$ to give a range of $\mathrm{pH}$ values $(6 \cdot 4,7 \cdot 7,8 \cdot 0,9 \cdot 0$ and $9 \cdot 4:$ measured after solidification using a flat-bottomed $\mathrm{pH}$ electrode). Tolerance of the test strains to chemicals was tested by incorporating the following chemicals individually into ISG medium before autoclaving: $1 \%$ and $0.1 \%(\mathrm{w} / \mathrm{v})$ phenol, $4 \%, 7 \%$ 
and $10 \%(\mathrm{w} / \mathrm{v})$ sodium chloride, $0.05 \%$ and $0.5 \%(\mathrm{w} / \mathrm{v})$ cobalt chloride. Requirements for metals were determined by either omitting one of $\mathrm{K}_{2} \mathrm{HPO}_{4}, \mathrm{CaCO}_{3}$ or $\mathrm{MgSO}_{4} .7 \mathrm{H}_{2} \mathrm{O}$ from the ISG formulation or one of the components of the trace metal supplement $\left(\mathrm{MnCl}_{2} .4 \mathrm{H}_{2} \mathrm{O}, 0.79 \mathrm{~g}\right.$ $1^{-1} ; \mathrm{CuSO}_{4} .5 \mathrm{H}_{2} \mathrm{O}, 0.64 \mathrm{~g} \mathrm{l}^{-1} ; \mathrm{FeSO}_{4} .7 \mathrm{H}_{2} \mathrm{O}, 0 \cdot 11 \mathrm{~g} \mathrm{l}^{-1} ; \mathrm{ZnSO}_{4} \cdot 7 \mathrm{H}_{2} \mathrm{O}$, $\left.0.15 \mathrm{~g} \mathrm{l}^{-1}\right)$. The test for vitamin requirement involved the addition of a filter-sterilized vitamin supplement (biotin, $10 \mathrm{mg} \mathrm{l}^{-1}$; vitamin $\mathbf{B}_{12}$, $10 \mathrm{mg} \mathrm{l}^{-1}$; and vitamin $B_{1}, 50 \mathrm{mg} \mathrm{l}^{-1}$ ) to autoclaved ISG medium. Growth on the above modified media could be directly compared with that on the unamended ISG medium, which had a $\mathrm{pH}$ value of $7 \cdot 2$, a sodium chloride content of $0.1 \%$, a full trace element supplement, and an incubation temperature of $28^{\circ} \mathrm{C}$.

Inoculation, incubation and growth measurement. The test media were distributed into 25-compartment 'Replidishes' (Sterilin) ( $3 \mathrm{ml}$ per well) and allowed to set. Each well was spot-inoculated with a test organism using a multi-point inoculator. The inoculum consisted of a suspension in water of actinomycete spores (from a 7-14-d-old culture) or bacterial cells (from a 3-5-d-old culture). The suspensions were also used to inoculate maintenance media to ensure that a heavy inoculum had been achieved. Incubation was at $28^{\circ} \mathrm{C}$ for $14 \mathrm{~d}$ unless otherwise stated. Colony diameter measurements taken after incubation provided quantitative data for each test. These data were also converted to binary format [i.e. growth (1) and no growth (0)] by allocating a value of 1 to any measurement greater than zero.

Coding of data. Two data matrices with information from 43 tests on each of the 74 test organisms were prepared. One consisted of the continuous colony measurements (in millimetres) whilst the second was in binary format. Continuous data were transformed by standardization prior to analysis (i.e. expressed as numbers of standard deviations). This is important because the similarity coefficients of data that are not standardized will be biased towards those variables with large variances. The two types of coding (continuous versus binary) were carried out to determine whether it was necessary to measure the size of individual colonies (a time-consuming exercise) in order to obtain the necessary discrimination or whether a simple growth/no growth determination would suffice.

Data analysis. SDA was carried out using the statistical package SPSS $^{\mathrm{x}}$, release 2.1 (SPSS Inc., Chicago, USA). For the design of new culture media for antibiotic-producing actinomycetes, discriminant analysis was carried out twice, first to find selective pressures that enhanced the competitiveness of actinomycetes compared with eubacteria, and then to find conditions that selectively encouraged antibiotic-producing actinomycetes over non-producing actinomycetes.

Evaluation of selective substrates for actinomycetes and antibioticproducing actinomycetes. Selective substrates found by carrying out SDA on the physiological and nutritional test data were incorporated into simple isolation media. Humic acid $(0.1 \%)$ and proline $(1 \%)$ were tested in two separate isolation media using, as a base, the carbon and nitrogen utilization test basal medium described above. In two further test media either asparagine or proline was substituted for nitrate in M3 medium at an equivalent nitrogen level. All media were adjusted to pH 7.2. Spread plates of the test media were prepared using appropriate dilutions of the Puttenham barley field soil. Incubation was at $28^{\circ} \mathrm{C}$ for $14 \mathrm{~d}$, after which the actinomycete colonies were counted and picked off for antibiotic assay using the agar droplet method described above. The results were compared with those on unamended M3 medium and starch/casein/nitrate medium (formulations in current use for industrial screening programmes). The evaluation was repeated at three different times of year in order to account for seasonal variation.

\section{Results and Discussion}

\section{Antibiotic-producing ability of the isolates}

Of the 49 actinomycete test strains included in the study, 19 were shown to be capable of antibiotic production in the test system described whilst none of the eubacteria were capable of producing antibiotic substances. The information on antibiotic production was not included in the data matrix for analysis but was used to allocate the actinomycete test strains to different groups for SDA.

\section{Discriminant analysis of actinomycetes versus eubacteria}

There are two methods by which independent variables are selected for inclusion in discriminant analysis. All independent variables may be entered concurrently or variables may be entered in a stepwise fashion. The stepwise method was used for this study. Variables were selected for entry into the analysis on the basis of their discriminatory power. In many cases the full set of variables contains excess information about group differences; some of the variables may not be very useful in discriminating among groups and may even lead to an increased number of misclassifications. Using the stepwise procedure, weak or redundant variables are eliminated from the analysis when they no longer make a sufficient contribution to the discriminant function, although they remain eligible for reselection at a future step.

Rao's $V$ (e.g. Norusis, 1985) was used as the criterion for the stepwise selection of the variables into discriminant analysis. It was felt that this measure was the most applicable to the selection of tests for media design. Rao's $V$ maximizes group separation without necessarily increasing group cohesiveness. Maximization of group separation would have an optimal effect on medium selectivity whilst an increase in group cohesiveness (which can be achieved using other measures such as Wilks' Lambda or the partial $F$ ratio: e.g. Norusis, 1985) would not be justified since the group members could not be assumed to be closely related prior to analysis (they were known to be at least morphologically distinct).

Using the stepwise procedure (Table 1) a list of the most important discriminating variables is produced together with a list of the standardized discriminant function coefficients. Each coefficient represents the relative contribution of its associated variable to that function. Hence, the coefficient is, in effect, a measure of the discriminatory power of that variable within the function. It can be seen that the recommendations from discriminant analysis are broadly similar using either continuous or binary data. Growth at a starting $\mathrm{pH}$ of $7 \cdot 7$, utilization of proline as a combined carbon and 
Table 1. Discriminant variables for actinomycetes and eubacteria

\begin{tabular}{|c|c|c|c|}
\hline \multicolumn{2}{|l|}{ Continuous data } & \multicolumn{2}{|l|}{ Binary data } \\
\hline Variable* & $\begin{array}{l}\text { Discriminant } \\
\text { function }\end{array}$ & Variable* & $\begin{array}{l}\text { Discriminant } \\
\text { function }\end{array}$ \\
\hline \multicolumn{4}{|c|}{ Selective substrates for actinomycetes } \\
\hline $\begin{array}{l}\text { pH } 7 \cdot 7 \text { (ISG medium) } \\
\text { Glycerol }(1 \%) \text { as } \mathrm{C} \text { source } \\
\text { Glucose }(1 \%) \text { as } \mathrm{C} \text { source } \\
\text { Proline }(1 \%) \text { as } \mathrm{C} \text { and } \mathrm{N} \text { source } \\
\text { Nitrate as } \mathrm{N} \text { source } \\
\text { Starch }(1 \%) \text { as } \mathrm{C} \text { source } \\
\mathrm{CaCO}_{3} \text { omitted (ISG medium) }\end{array}$ & $\begin{array}{l}-0.78 \\
-0.54 \\
-0.48 \\
-0.43 \\
-0.27 \\
-0.28 \\
-0.21\end{array}$ & $\begin{array}{l}\text { pH } 7 \cdot 7 \text { (ISG medium) } \\
\text { Proline }(1 \%) \text { as } \mathrm{C} \text { and } \mathrm{N} \text { source } \\
\text { Humic acid }(0.1 \%) \text { as } \mathrm{C} \text { and } \mathrm{N} \text { source } \\
\text { Glucose }(1 \%) \text { as } \mathrm{C} \text { source } \\
\text { pH } 8 \text { (ISG medium) } \\
\text { Propionate }(1 \%) \text { as } \mathrm{C} \text { source } \\
\text { Methanol }(1 \%) \text { as } \mathrm{C} \text { source }\end{array}$ & $\begin{array}{l}-0.92 \\
-0.90 \\
-0.56 \\
-0.52 \\
-0.40 \\
-0.36 \\
-0.36\end{array}$ \\
\hline \multicolumn{4}{|c|}{ Selective substrates for eubacteria } \\
\hline $\begin{array}{l}\text { Aspartate ( } 1 \% \text { ) as } \mathrm{C} \text { and } \mathrm{N} \text { source } \\
\text { Vitamins (ISG medium) } \\
\text { Alanine as } \mathrm{N} \text { source } \\
\text { pH } 6.4 \text { (ISG medium) } \\
\text { Propionate }(0.1 \% \text { ) as } \mathrm{C} \text { source } \\
\text { Tolerance to } 0.05 \% \text { cobalt } \\
\text { Tolerance to } 0.1 \% \text { phenol }\end{array}$ & $\begin{array}{l}1.06 \\
0.63 \\
0.54 \\
0.52 \\
0.52 \\
0.41 \\
0.29\end{array}$ & $\begin{array}{l}\text { Aspartate }(1 \%) \text { as } \mathrm{C} \text { and } \mathrm{N} \text { source } \\
\text { Glucose }(0.1 \%) \text { as } \mathrm{C} \text { source } \\
\text { Alanine as nitrogen source } \\
\text { Tolerance to } 0.05 \% \text { cobalt } \\
\text { Threonine }(1 \%) \text { as } \mathrm{C} \text { and } \mathrm{N} \text { source } \\
\text { Humic acid }(1 \%) \text { as } \mathrm{C} \text { and } \mathrm{N} \text { source } \\
\text { Ammonia as } \mathrm{N} \text { source } \\
\text { pH } 6.4 \text { (ISG medium) } \\
30^{\circ} \mathrm{C} \text { (ISG medium) } \\
\text { Glutamic acid as } \mathrm{N} \text { source }\end{array}$ & $\begin{array}{l}1 \cdot 15 \\
0.93 \\
0.39 \\
0 \cdot 33 \\
0 \cdot 29 \\
0.27 \\
0.26 \\
0 \cdot 24 \\
0.23 \\
0.20\end{array}$ \\
\hline
\end{tabular}

* Percentages of carbon source quantities in parentheses refer to carbon levels equivalent to either $1 \%$ glucose or $0.1 \%$ glucose.

nitrogen source and glucose $(1 \%, w / v)$ as a carbon source were listed by both analyses as factors suitable for the selection of actinomycetes. Growth on aspartate, resistance to $0.05 \%$ cobalt and growth at a starting $\mathrm{pH}$ of 6.4 feature in both lists as positive characters for eubacteria and are, therefore, conditions to be avoided in actinomycete isolation media that do not contain antibacterial inhibitors.

Alkaline $\mathrm{pH}$ has frequently been used for the selective isolation of actinomycetes in the past. An extreme example is the adjustment of isolation media to $\mathrm{pH} 10$ (Ho \& Ko, 1980), which was found to be almost exclusively selective for actinomycetes. Glucose and proline have not frequently been used in isolation media for actinomycetes. However, glucose $(1 \%, w / v)$ as a sole source of carbon and proline and asparagine $(0.1 \%, \mathrm{w} / \mathrm{v})$ as sole sources of nitrogen (with glucose as the carbon source) were deleted from the data matrix of Williams et al. $(1983 a)$ as all actinomycete strains included in the taxonomic study grew well on these substrates, which therefore were of no taxonomic value. The selective effect of glucose in the carbon utilization basal medium may have been related to the presence of ammonium sulphate in this basal medium. Use of ammonium chloride in a glucose-containing medium (ISG) did not have an inhibitory effect on eubacteria, in fact eubacteria were favoured. This anomaly shows that great care needs to be taken in interpretation of the results, and differences in basal medium must be particularly kept in mind.

Glycerol, starch and nitrate were also listed as possible selective substrates for actinomycetes when continuous data were used. These compounds have commonly been included in selective isolation media for actinomycetes in the past. For example, starch and nitrate are used in combination in starch/casein/nitrate medium (Kuster \& Williams, 1964); nitrate is the sole nitrogen source in M3 medium (Rowbotham \& Cross, 1977); glycerol is used in both glycerol/arginine medium (Porter et al., 1960) and glycerol/asparagine medium (Pridham \& Lyons, 1961) and may be substituted for glucose in starch/casein/ nitrate medium (Kuster \& Williams, 1964).

When binary data were used, $0.1 \%$ humic acid, $1 \%$ propionate and methanol were listed as additional discriminators for actinomycetes, whilst $0.1 \%$ glucose was listed as a discriminator for eubacteria even though $1 \%$ glucose had been recommended for discrimination of actinomycetes. This result implies that as glucose becomes depleted the selectivity of the medium may be reversed. Humic acid is a substrate which has long been linked with actinomycetes in nature, and in recent years humic-acid-containing media have received some attention (Hayakawa \& Nonomura, 1987). There is also evidence that soil humic acids may influence the distribution of actinomycetes in different soils (Hayakawa et al., 1988). 
Table 2. Discriminant variables for actinomycetes: antibiotic producers versus non-producers

\begin{tabular}{|c|c|c|c|}
\hline \multicolumn{2}{|l|}{ Continuous data } & \multicolumn{2}{|l|}{ Binary data } \\
\hline Variable* & $\begin{array}{l}\text { Discriminant } \\
\text { function }\end{array}$ & Variable* & $\begin{array}{l}\text { Discriminant } \\
\text { function }\end{array}$ \\
\hline \multicolumn{4}{|c|}{ Selective substrates for antibiotic producers } \\
\hline $\begin{array}{l}\text { Proline ( } 1 \%) \text { as } \mathrm{C} \text { and } \mathrm{N} \text { source } \\
\text { Glucose }(1 \%) \text { as } \mathrm{C} \text { source } \\
\mathrm{K}_{2} \mathrm{HPO}_{4} \text { omitted (ISG medium) } \\
\text { Asparagine as } \mathrm{N} \text { source } \\
\text { Resistance to cobalt }(0.05 \%) \\
\text { Glycerol }(1 \%) \text { as } \mathrm{C} \text { source } \\
\text { Zinc omitted (ISG medium) } \\
\text { Alanine as } \mathrm{N} \text { source } \\
\text { Humic acid }(0.1 \%) \text { as } \mathrm{C} \text { and } \mathrm{N} \text { source }\end{array}$ & $\begin{array}{l}-1.93 \\
-1.60 \\
-1.51 \\
-1.39 \\
-1.30 \\
-0.92 \\
-0.87 \\
-0.86 \\
-0.69\end{array}$ & $\begin{array}{l}\text { Vitamins added (ISG medium) } \\
\text { Resistance to cobalt }(0.05 \%) \\
\text { Ammonia as N source } \\
\text { pH } 7 \cdot 7 \text { (ISG medium) } \\
\text { Asparagine as N source } \\
\text { Proline }(1 \%) \text { as C and N source } \\
\text { Starch }(1 \%) \text { as C source }\end{array}$ & $\begin{array}{l}-0.94 \\
-0.73 \\
-0.69 \\
-0.64 \\
-0.56 \\
-0.55 \\
-0.38\end{array}$ \\
\hline \multicolumn{4}{|c|}{ Selective substrates for antibiotic non-producers } \\
\hline $\begin{array}{l}\text { Threonine ( } 1 \% \text { ) as } \mathrm{C} \text { and } \mathrm{N} \text { source } \\
\text { Magnesium omitted (ISG medium) } \\
\text { Copper omitted (ISG medium) } \\
28^{\circ} \mathrm{C} \text { (ISG medium) } \\
30^{\circ} \mathrm{C} \text { (ISG medium) } \\
\text { Glucose }(0 \cdot 1 \%) \text { as } \mathrm{C} \text { source } \\
\text { Nitrate as } \mathrm{N} \text { source } \\
\text { Humic acid }(1 \%) \text { as } \mathrm{C} \text { and } \mathrm{N} \text { source } \\
\text { Propionate }(1 \%) \text { as } \mathrm{C} \text { source }\end{array}$ & $\begin{array}{l}3.43 \\
2.30 \\
1.61 \\
1.28 \\
0.69 \\
0.66 \\
0.59 \\
0.50 \\
0.39\end{array}$ & $\begin{array}{l}\text { Humic acid ( } 1 \% \text { ) as } \mathrm{C} \text { and } \mathrm{N} \text { source } \\
\text { Nitrate as } \mathrm{N} \text { source } \\
\text { Magnesium omitted (ISG medium) } \\
28^{\circ} \mathrm{C} \text { (ISG medium) } \\
\text { Methanol ( }(1 \% \text { ) as } \mathrm{C} \text { source }\end{array}$ & $\begin{array}{l}1 \cdot 53 \\
1.34 \\
0.85 \\
0 \cdot 59 \\
0 \cdot 41\end{array}$ \\
\hline
\end{tabular}

\section{Discriminant analysis of antibiotic producers versus non- producers}

Table 2 shows the results of discriminant analysis of both the continuous and binary data set of the actinomycete strains. Proline, asparagine and cobalt $(0.05 \%)$ appear to be important selective substrates for antibiotic-producing actinomycetes whilst nitrate and the absence of magnesium appear to be selective against antibiotic producers. The continuous data also indicate the inhibition of antibiotic producers by zinc and potassium/ phosphate, as well as the possible importance of glucose $(1 \%, w / v)$, glycerol and humic acid $(0.1 \%)$ as substrates for antibiotic-producing actinomycetes. When binary data were used, growth in the presence of vitamins was listed as the most selective discriminator for actinomycetes. Vitamins are sometimes included in isolation media targeted toward rare, non-streptomycete actinomycetes. However, they are frequently omitted in less specialized isolation media.

In the past, antibiotic-producing actinomycetes have not been directly targeted at the isolation stage (except via the use of antibiotic resistance). Therefore, we have no information concerning existing selective substrates and conditions for this group of organisms. However, some of the substrates listed by discriminant analysis have parallels in antibiotic production media. Ammonia as a nitrogen source is often used in antibiotic production media as it is a cheap and readily utilizable nitrogen source for most bacteria. Also, many amino acids (e.g. asparagine, alanine, arginine and glutamine) are known to support antibiotic production (Aharonowitz \& Demain, 1979; Shen et al., 1984). Furthermore, amino acids may be particularly useful alternative nitrogen sources in antibiotic fermentations where ammonia represses antibiotic production. In the analysis of binary data the listing of ammonia with a coefficient of -0.69 , and of asparagine and proline with coefficients of -0.56 and -0.55 , respectively, would appear to circumstantially corroborate the experience with antibiotic production media. The appearance of cobalt resistance as a discriminator for antibiotic-producing actinomycetes is also interesting. It is known that $\beta$-lactam antibiotics complex metal ions at high concentrations (Fazerkerly \& Jackson, 1975). As a result of this observation, it is thought that strains which become resistant to these metallic ions do so by overproducing $\beta$-lactam antibiotics as a means of detoxification (Chang \& Elander, 1979). As part of a strain improvement programme, Onadipe \& Bushell (1987) found that media containing $0.05 \%$ cobalt chloride selected for high-titre antibiotic-producing UVradiation-induced mutants of Streptomyces cattleya.

Some of the selective substrates for antibiotic-producing actinomycetes were also selective for eubacteria (e.g. $0.05 \%$ cobalt). Such substrates may not be suitable for inclusion in primary isolation media but could, perhaps, 
be used in a late stage of a multistage isolation procedure or in the presence of antibacterial inhibitors, that is, where large numbers of eubacteria have been eliminated or suppressed.

\section{Reproducibility of results}

A preliminary study showed that the reproducibility of colony diameter measurements on the test media was high. The average error, based on 72 observations with 18 different organisms, was $1.5 \%$. As a result of this finding, duplicate cultures were not included in the final study. The results of SDA of the binary and continuous data matrices were broadly similar. However, in the case of discrimination between antibiotic producers and nonproducers, continuous data were required for greater $(>90 \%)$ resolution. Whilst continuous data contain more detailed information, they are more prone to errors.

One criticism of discriminant analysis is that the content of the list of discriminating variables relies heavily on the first few variables in that list. For example, if variables $A$ and $B$ collectively recover $80 \%$ of the organisms in a particular group, then discriminant analysis will seek a variable $\mathrm{C}$, which results in recovery of the remaining $20 \%$ of the group members. Removal of one of the first few variables from the database may greatly change the content of the discriminant list. Removal from the data matrix of information such as growth on proline or at $\mathrm{pH} 7.7$ on ISG medium had a large effect on the results of the analysis. Such omissions resulted in major changes in the content of the list of discriminating isolation conditions and reduced the correct classification rate. Omitting substrates with low coefficient values from the analysis caused only minor changes in the content of the discriminant list, and little change in the correct classification rate. However, this shows that substrates with high coefficients are indeed powerful discriminators and that those with lower coefficients might be replaced by other substrates. Because omitting some of the test strains from the analyses had little effect, it was concluded that the results of the analyses were stable.

\section{Isolation medium effects}

Media with varied and complex compositions were chosen because nutrients used during isolation of the study organisms could have influenced their performances in the tests. To assess this possibility, SDA was carried out with the organisms grouped according to the medium they had been isolated from. The results showed that the isolation medium grouping could not achieve accurate discrimination. The isolation media constituents did not appear in the Rao's stepwise discriminant variable listing and, furthermore, poor $(<50 \%)$ correct classification rates were encountered. This indicates that the selective media used were not selective for organisms with restricted physiological and nutritional capabilities. It can be concluded that the isolation media had no significant influence on the subsequent performance of the isolates in the nutritional and physiological tests.

\section{Practical evaluation of selective substrates for actinomycetes and antibiotic-producing actinomycetes}

Simple isolation media incorporating some of the selective substrates found by discriminant analysis of the physiological and nutritional test data were tested using soil inocula. For the initial evaluation, media containing either proline, humic acid $(0.1 \%)$ or asparagine were chosen. Proline and humic acid $(0 \cdot 1 \%)$ had been listed by discriminant analysis as selective carbon and nitrogen sources for the isolation of actinomycetes. Proline had also been recommended for the selection of antibioticproducing actinomycetes. Asparagine as a nitrogen source in combination with glucose was identified by discriminant analysis for the selection of antibiotic producers but was not expected to be selective against eubacteria. Therefore, the M3 medium of Rowbotham \& Cross (1977) was modified by substituting asparagine for nitrate (a negative discriminator for both actinomycetes and antibiotic producers in this study). A second modified M3 medium was also tested, this time with proline substituting for nitrate and propionate. Two further isolation media consisted of the carbon and nitrogen utilization test base with either proline $(1 \%)$ or humic acid $(0.1 \%)$ added. With the exception of some of the September results, all four media were successful in increasing the percentage of actinomycetes isolated compared to starch/casein/nitrate medium and unmodified M3 medium (Fig. 1). Furthermore, much improved isolation rates of antibiotic-producing actinomycetes were observed as a result of the increased competitiveness of antibiotic producers on these selective substrates (Fig. 2). Some seasonal variation was encountered, particularly in the proportion of antibiotic producers, but the percentage isolated was always higher than that obtained on the two control media. The lowest proportion of actinomycetes, obtained in June, was due to a marked increase in the number of eubacteria present in the soil. The selectivity of the media for actinomycetes capable of antibiotic production was maintained despite increased competition between actinomycetes and eubacteria. These findings, which imply that the ability to produce a secondary metabolite can confer a growth rate advantage, suggest a relationship between primary and secondary metabolism which is more subtle than that arising from the self-defence role often assumed for antibiotic production. 


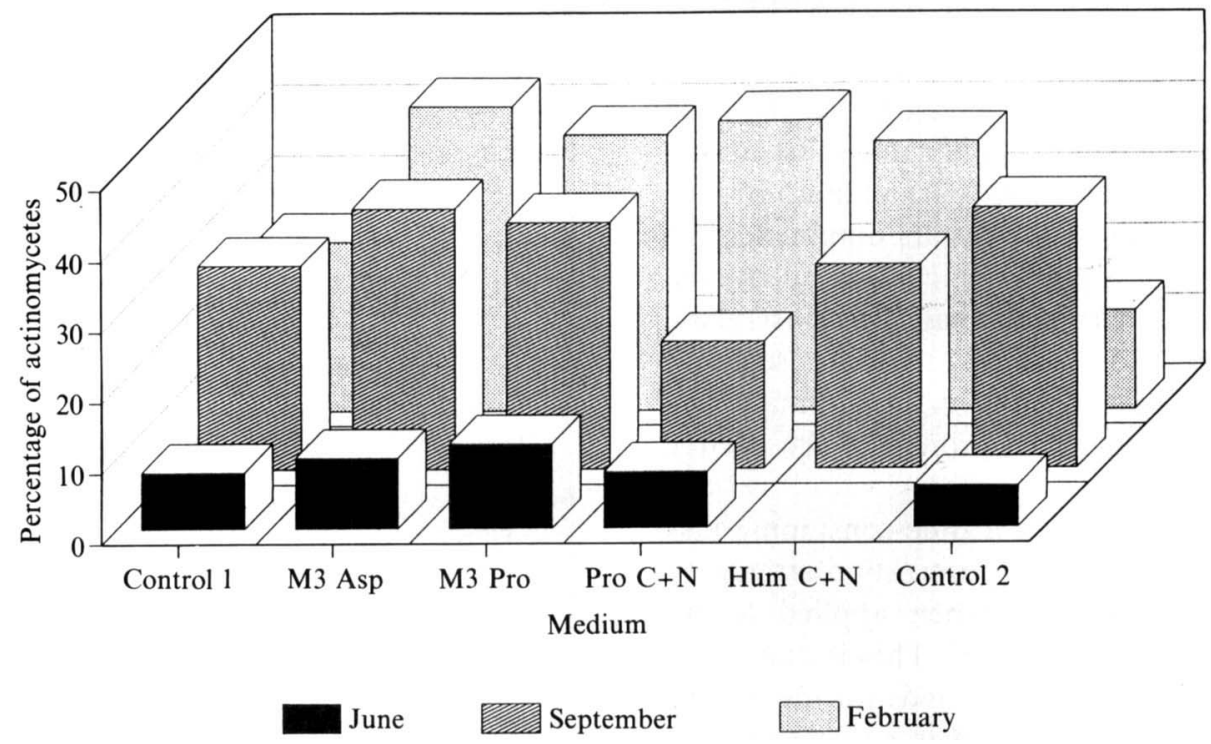

Fig. 1. Percentage of actinomycetes isolated on the test media at different times of the year. Abbreviations: Control 1, the M3 medium of Rowbotham \& Cross (1977); Control 2, the starch/casein/nitrate medium of Kuster \& Williams (1964); M3 Asp, M3 substituted with asparagine as described in the text; M3 Pro, M3 substituted with proline as described in the text; $\mathrm{C}+\mathrm{N}$, carbon and nitrogen utilization test basal medium as described in the text; Hum, humic acid. No data are available for humic acid $\mathrm{C}+\mathrm{N}$ medium for the June experiment.

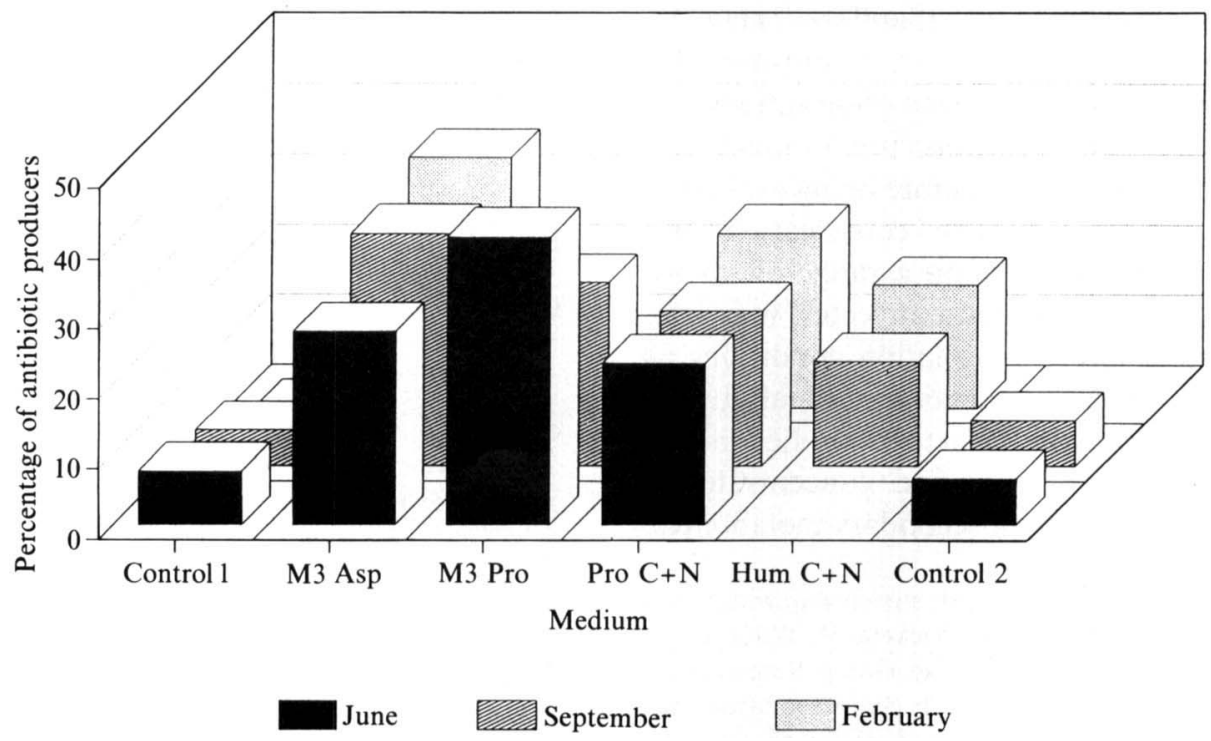

Fig. 2. Percentage of antibiotic-producing actinomycetes isolated on the test media at different times of the year. Abbreviations as in Fig. 1. No data are available for humic acid $\mathrm{C}+\mathrm{N}$ medium for the June experiment or for the control 2 February experiment.

Discriminant analysis of physiological and nutritional data on a population of soil bacteria was successful in identifying sub-populations (or clusters) of actinomycetes and eubacteria. Furthermore, clusters of antibioticproducing actinomycetes could be identified, although information concerning antibiotic production per se was not included in the data matrix. Using the selective subtrates identified by stepwise discriminant analysis it was possible to selectively isolate this group of organisms (Fig. 1).

Theoretically, the effectiveness of the selective substrates listed by discriminant analysis may be maximized if all of the substrates and conditions are combined into a single selection regime. However, in this work it was found that the most selective substrates identified by SDA were sufficiently powerful to lead to the selection of 
the desired groups when used singly. Isolation media incorporating combinations of selective substrates may lead to improved selective isolation media, but it should be remembered that the behaviour of some substrates in combination (particularly multiple carbon and nitrogen sources) may be different to the results obtained when they are tested singly in a physiological and nutritional study. Nevertheless, discriminant analysis is a useful aid to medium optimization; it not only identifies selective substrates but it also finds the optimal combination of selective substrates for maximal growth of the desired group of organisms.

Medium optimization can be a time-consuming task (we have reviewed alternative optimization strategies: Bull et al., 1990), particularly when applied to the isolation of actinomycetes from soil. This is due to the difficulty of designing objective methods for the evaluation of medium efficacy. Populations in natural environments demonstrate great diversity depending on environmental conditions. The efficacy of a selective medium in one environment, for example, may be quite different in another environment or it may show considerable seasonal variation depending on the proportions of different micro-organisms present at one time. The use of statistical methods and models, therefore, may be advantageous in providing a simplified description of a natural system from which generalized observations can be made, and from which optimization programmes may be sought and tested theoretically before being evaluated in the natural environment. The construction and exploration of suitable databases on a range of microorganisms, including the rarer actinomycetes, may lead to the design of more effective isolation conditions as well as an improved understanding of microbial physiology and medium specificity. Further studies might include known reference strains and concentrate on producers of particular classes of secondary metabolites.

T.A.H. was supported by an SERC CASE studentship with Glaxo Group Research. We wish to thank J. C. Vickers, H. Wildman, B. Middleton, M. Hayes and D. Langley (Glaxo Group Research) for valuable discussions, and T. N. Bryant and J. E. Smith for introducing us to the potential of discriminant analysis and related procedures.

\section{References}

Aharonowitz, Y. \& Demain, A. L. (1979). Nitrogen nutrition and regulation of cephalosporin production in Streptomyces clavuligerus. Canadian Journal of Microbiology 25, 61-67.

BERDY, J. (1989). The discovery of new bioactive microbial metabolites: screening and identification. In Bioactive Microbial Metabolites (Progress in Industrial Microbiology, vol. 27), pp. 3-25. Edited by M. E. Bushell \& U. Graefe. Amsterdam: Elsevier.

Bull, A. T., Huck, T. A. \& Bushell, M. E. (1990). Optimization strategies in microbial process development and operation. In Microbial Growth Dynamics, pp. 145-168. Edited by R. K. Poole, M. J. Bazin \& K. W. Keevil. Oxford: Oxford University Press.
Bushell, M. E. (1982). Microbiological aspects of the discovery of novel secondary metabolites. In Topics in Enzyme and Fermentation Technology, vol. 6, pp. 32-67. Edited by A. Wiseman. Chichester: Ellis Horwood.

BusHell, M. E. (1983). Search and discovery of novel microbial metabolites. In Progress in Industrial Microbiology, vol. 17, pp. 1-6. Edited by M. E. Bushell. Amsterdam: Elsevier.

Bushell, M. E. \& Nisbet, L. J. (1981). A technique for eliminating recurring producers of known metabolites in antibiotic screens. Zentralblatt für Bakteriologie, Mikrobiologie und Hygiene. 1. Abteilung, Supplement 11, 507-514.

Chang, L. T. \& Elander, R. P. (1979). Rational selection for improved cephalosporin $\mathrm{C}$ productivity in strains of Acremonium chrysogenum Gams. Developments in Industrial Microbiology 20, 367379.

Fazerkerly, G. V. \& JACKson, G. E. (1975). Metal ion coordination by some penicillin and cephalosporin antibiotics. Journal of Inorganic and Nuclear Chemistry 37, 2371-2375.

GoRDON, R. E. \& MirM, J. M. (1962). The identification of Nocardia caviae (Erikson) nov. comb. Annals of the New York Academy of Sciences 98, 628-636.

Hayakawa, M. \& Nonomura, H. (1987). Humic acid-vitamin agar, a new medium for the selective isolation of soil actinomycetes. Journal of Fermentation Technology 65, 501-509.

HayakaWA, M., IshizaWA, K. \& NonOMURA, H. (1988). Distribution of rare actinomycetes in Japanese soils. Journal of Fermentation Technology 66, 367-373.

Ho, W. C. \& Ko, W. H. (1980). A simple medium for the selective isolation and enumeration of soil actinomycetes. Annals of the Phytopathology Society of Japan 46, 634-638.

KUSTER, E. \& WILliams, S. T. (1964). Selection of media for isolation of streptomycetes. Nature, London 202, 928.

Lechevalier, M. P. \& Lechevalier, H. (1970). Chemical composition as a criterion in the classification of aerobic actinomycetes. International Journal of Systematic Bacteriology 20, 435-443.

Nolan, R. D. \& Cross, T. (1988). Isolation and screening of actinomycetes. In Actinomycetes in Biotechnology, pp. 1-32. Edited by $M$. Goodfellow, S. T. Williams \& M. Mordarski. London: Academic Press.

NoRUSIs, M. J. (1985). SPSS ${ }^{X}$ Advanced Statistics Guide. New York: McGraw-Hill.

OKami, Y. \& HotTA, K. (1988). Search and discovery of new antibiotics. In Actinomycetes in Biotechnology, pp. 33-67. Edited by M. Goodfellow, S. T. Williams \& M. Mordarski. London: Academic Press.

ONADIPE, A. O. \& Bushell, M. E. (1987). The use of multivariate analysis for the design of selective isolation conditions for mutants of Streptomyces cattleya with improved antibiotic titre. Journal of Chemical Technology and Biotechnology 39, 237-249.

Porter, J. N., Wilhelm, J. J. \& TResner, H. D. (1960). Method for the preferential isolation of actinomycetes from soils. Applied Microbiology 8, 174-178.

Pridham, T. G. \& Lyons, A. J. (1961). Streptomyces albus (RossiDoria) Waksman et Henrici: taxonomic study of strains labelled Streptomyces albus. Journal of Bacteriology 81, 431-441.

Pridham, T. G., ANderson, P., Foley, C., Lindenfelser, .L. A., Hesseltine, C. W. \& Benedict, R. G. (1957). A selection of media for maintenance and taxonomic study of Streptomyces. Antibiotics Annual 1956/7, 947-953.

Rowbotham, T. J. \& Cross, T. (1977). Ecology of Rhodococcus coprophilus and associated actinomycetes in freshwater and agricultural habitats. Journal of General Microbiology 100, 231-240.

Shen, Y. Q., Heim, J., Solomon, N. A., Wolfe, S. \& Demain, A. L. (1984). Repression of $\beta$-lactam production in Cephalosporium acremonium by nitrogen sources. Journal of Antibiotics 37, 503-511.

SHIRLING, E. B. \& GoTTLEIB, D. (1966). Methods of characterization of Streptomyces species. International Journal of Systematic Bacteriology 16, 313-340.

Vickers, J. C., Williams, S. T. \& Ross, G. W. (1984). A taxonomic approach to the selective isolation of streptomycetes from soil. In Biological, Biochemical and Biomedical Aspects of Actinomycetes, pp. 553-561. Edited by L. Ortiz-Ortiz, L. F. Bojalil \& V. Yakoleff. Orlando: Academic Press. 
Williams, S. T., Davies, F. L. \& Hall, D. M. (1969). A practical approach to the taxonomy of actinomycetes isolated from soil. In The Soil Ecosystem, pp. 107-117. Edited by J. G. Shields. London: Academic Press.

Williams, S. T., Goodfellow, M., Alderson, G., Wellington, E. M. H., SNeath, P. H. A. \& SaCkin, M. J. (1983a). Numerical classification of Streptomyces and related genera. Journal of General Microbiology 129, 1743-1813.

Williams, S. T., Goodfellow, M., Wellington, E. M. H., Vickers, J. C., Alderson G., Sneath, P. H. A., Sackin, M. J. \& Mortimer, A. M. $(1983 b)$. A probability matrix for the identification of some streptomycetes. Journal of General Microbiology 129, 1815-1830. 